\title{
An experience selecting quality features of apps for people with disabilities using abductive approach to explanatory theory generation
}

\author{
Andres Larco ${ }^{\text {Corresp., } 1}{ }^{,}$, Carlos Montenegro ${ }^{1}$, Cesar Yanez $^{1}$, Sergio Luján-Mora ${ }^{2}$ \\ 1 Departamento de Informática y Ciencias de la Computación, Escuela Politécnica Nacional, Quito, Pichincha, Ecuador \\ 2 Department of Software and Computing Systems, Universidad de Alicante, Alicante, Alicante, Spain \\ Corresponding Author: Andres Larco \\ Email address: andres.larco@epn.edu.ec
}

This study determines one of the most relevant quality factors of apps for people with disabilities utilizing the abductive approach to the generation of an explanatory theory. First, the abductive approach was concerned with the results' description, established by the apps' quality assessment, using the Mobile App Rating Scale (MARS) tool. However, because of the restrictions of MARS outputs, the identification of critical quality factors could not be established, requiring the search for an answer for a new rule. Finally, the explanation of the case (the last component of the abductive approach) to test the rule's new hypothesis. This problem was solved by applying a new quantitative model, compounding data mining techniques, which identified MARS' most relevant quality items. Hence, this research defines a much-needed theoretical and practical tool for academics and also practitioners. Academics can experiment utilizing the abduction reasoning procedure as an alternative to achieve positivism in research. This study is a first attempt to improve the MARS tool, aiming to provide specialists relevant data, reducing noise effects, accomplishing better predictive results to enhance their investigations. Furthermore, it offers a concise quality assessment of disability-related apps. 


\section{An experience selecting quality features of apps for} 2 people with disabilities using the abductive approach 3 to explanatory theory generation

${ }^{1}$ Departamento de Informática y Ciencias de la Computación, Escuela Politécnica Nacional, 9 Quito, Pichincha, Ecuador

${ }^{2}$ Department of Software and Computing Systems, University of Alicante, Alicante, Alicante, Spain

Andres Larco ${ }^{1}$, Carlos Montenegro ${ }^{1}$, Cesar Yanez ${ }^{1}$, Sergio Luján-Mora ${ }^{2}$

Corresponding Author:

Andres Larco ${ }^{1}$

Ladrón de Guevara E11-253 y Andalucía, Quito, Pichincha, 17-01-2759, Ecuador

Email address: andres.larco@epn.edu.ec

\section{Abstract}

This study determines one of the most relevant quality factors of apps for people with disabilities utilizing the abductive approach to the generation of an explanatory theory. First, the abductive approach was concerned with the results' description, established by the apps' quality assessment, using the Mobile App Rating Scale (MARS) tool. However, because of the restrictions of MARS outputs, the identification of critical quality factors could not be established, requiring the search for an answer for a new rule. Finally, the explanation of the case (the last component of the abductive approach) to test the rule's new hypothesis. This problem was solved by applying a new quantitative model, compounding data mining techniques, which identified MARS' most relevant quality items. Hence, this research defines a much-needed theoretical and practical tool for academics and also practitioners. Academics can experiment utilizing the abduction reasoning procedure as an alternative to achieve positivism in research. This study is a first attempt to improve the MARS tool, aiming to provide specialists relevant data, reducing noise effects, accomplishing better predictive results to enhance their investigations. Furthermore, it offers a concise quality assessment of disability-related apps.

\section{Introduction}

There are several definitions of theory. One, established by Sjøberg et al. [1], depends on philosophical and practical issues and the field of study. However, Corley and Gioia [2] offer a more straightforward definition, a statement of theories and their interrelationships that shows how and why an exceptional event occurs. But Horvath's [3] theory explains the concepts and facts in a given context, matching ideas and events logically based on their meaning, which 
40 similarly indicates the limits of the theory, facilitates the applicability and permits the

41 recognition of new hypotheses to cover a broader field.

42 According to Wacker [4], a theory contains four components: definitions, domain, relationships,

43 and prediction. Aliseda [5] suggests that discovering an idea towards a new theory involves a

44 complicated process starting with the initial conception through to an acceptable conclusion,

45 thereby forming a new theory.

46 Nevertheless, according to Philipsen [6], knowledge production divides into three specific

47 categories: discovery, problem/domain definition, initial concepts, and also the context of

48 justification, theories testing, as well as hypotheses enhancement. Researchers understand reason

49 more readily than discovery.

50 The justification uses three interrelated types of reasoning. Ngwenyama [7] inferred that the

51 deduction probably assists in suggesting logical implications of rules to develop experiments for observation as well as testing. Induction enables the scientist to deduce general rules from the monitoring of consistencies in phenomena behavior. Abduction is primarily an inference of an explanation of the views analyzed by [7], [8]. Lastly, Kapitan [9] suggests abduction is the procedure of generating theories and also developing some of them; reduction extracts their testable effects while induction assesses them.

The primordial feature of the rule is the variable individual measurable property of a process being observed. Feature selection helps understand data, which reduces calculus requirement and the effect of dimensionality while additionally improving the predictor performance.

60 Consequently, the relevance of the attribute option is to select a subset of input variables that can 61 describe data, minimizing noise or irrelevant variables, and yet offer more accurate predictive 62 results [10], [11], [12]. An exploratory approach to related contributions shows little research has been conducted on the fore-mentioned topic. Thus, new experiences are required to amplify the application domain options and corroborating the relatively new abductive approach. The current study uses the abductive process to create theories to improve the formal application of the Mobile App Rating Scale (MARS) results [13], the tool used to evaluate apps quality for people with disabilities. The research estimates the evaluation of the tool's external consistency because the MARS tool results are unable to be used for identifying relevant and unique variables that represent the quality factors. The objective of this work is to simplify the MARS tool to increase its performance without losing the quality of the evaluation. As far as we know, this study is the first attempt to improve the MARS tool. The principal contribution is to provide specialists relevant data, reducing noise effects, and accomplishing better predictive results to enhance their investigations. The structure of the current study is: Section 2 presents background and related work that includes the definitions of abductive reasoning and its applications; Section 3 contains the research approach, in three stages: the result, the rule, and the case; Section 4 involves

78 discussions of the results obtained, while Section 5 presents various conclusions. 


\section{Background and related work}

81 Philipsen [6] and Ngwenyama [7] establish the distinctions between deductive, inductive, and

82

83

84

85

86

87

88

89

90

91

92

93

94

95

96

97

98

99

100

101

102

103

104

105

106

107

108

109

110

111

112

113

114

115

116

117

118

also abductive reasoning with the connections between the entities; rule, case, and result. These three forms of scientific thinking are presented in Figure 1.

Figure 1: Inference forms. (Adapted from Philipsen [6]).

The abductive reasoning process addresses the situation where the findings differ from the theory's anticipated result, which guides the research study. The starting point coincides with that of induction but is concerned with the search for an explanation of the results, which are complex to explain applying the initial guiding theory. The search for reason demands the need for a new hypothesis, leading to the specific investigated case [6]. Aliseda [5] assumes that abduction in the scientific sense refers to empirical progress, pragmatism, and epistemic change. O'Reilly [14] and [8] concluded that abduction is the only logical operation that permits new ideas. In testing theory, abduction develops phases of the knowledge-production process. New explanations will likely arise where there is a requirement to solve an anomaly and discover new methods of explaining the particular empirical phenomenon [6]. Philipsen et al. established the research gaps, and the results are considered vital factors for identifying inconsistencies. Aliseda [15] indicated logical abduction is relevant regarding issues of scientific explanation. More recently, logical abduction found a place in computationally oriented theories of belief change in Artificially Intelligence. Olsen and Gjerding [16] investigated the notion of abduction related to and can be applied in a scientific research study. Furthermore, it showed the most necessary treatments of abduction in modern times, and it tried to define various processing modalities, both as an autonomous research strategy and inference type, and in relation and contrast to induction and deduction.

According to Zelechowska et al. [17], abduction is a type of complex reasoning carried out to make sense of unusual or ambiguous phenomena or fill the gaps in our beliefs. Despite the ubiquity of abduction in professional and everyday problem-solving processes, little empirical research was dedicated to investigating this kind of reasoning. Most of them concentrated on products of abduction - abductive hypotheses. Rapanta [18] explored abductive reasoning as the most appropriate for students' arguments to emerge in a class discussion. Abductive reasoning embraces the concept of plausibility and defeasibility of both the premises and the conclusion. Mitchell [19] posits that pragmatism supports using various research techniques, which a continual cycle of inductive, deductive, and when proper, abductive reasoning creates practical knowledge and works as a rationale for a rigorous research study. Abductive reasoning was essential for explaining empirical phenomena relating to competition, primarily how the top United Kingdom and German multinationals developed various strategies for outsourcing. Moreover, applying different methods can lead to research and succeeding management choices that reflect both the interplay of social and scientific elements of the world today. The work of Mitchell [19]is focused on the strategies for outsourcing. This is in contrast to our work, as we concentrate on app quality.

Peer] Comput. Sci. reviewing PDF | (CS-2021:02:58241:1:0:NEW 14 May 2021) 
119 Fariha and Meliou [20] present the idea of an abduction-ready database, which precomputes

120

121

122

123

124

125

126

127

128

129

130

131

132

133

134

135

136

137

138

139

140

141

142

143

144

145

146

147

148

149

150

151

152

153

154

155

156

157 158

semantic features and related statistics, allowing semantic similarity-aware query intent discovery (SQUID) to achieve real-time performance. Also, an extensive empirical assessment was provided on three real-world datasets, consisting of user-intent case studies, demonstrating that SQUID is efficient and effective and outperforms machine learning techniques. In contrast to our research, there is no assessment of the quality of the apps for data processing.

Ganesan et al. [21] propose a probabilistic abductive reasoning method that enhances an existing rule-based Intrusion Detection Systems (IDS) to detect these evolved attacks by predicting rule conditions that are likely to occur and able to generate new snort rules when provided with seed rule to reduce the concern on experts to update them constantly. This is in contrast to our study, as we focused on feature assessment of apps.

Bhagavatula et al. [22] present the initial study that research the viability of language-based abductive reasoning. Also, conceptualize and introduce Abductive Natural Language Inference (ANLI) - a novel task focused on abductive reasoning in narrative contexts. The task is formulated as a multiple-choice question answering problem. Additionally, introduced Abductive Natural Language Generation (ANLG) - a novel task that requires machines to generate plausible hypotheses for given observations. In our study, we only focus on optimizing the MARS.

A review of related work shows that the abductive process has been used in various forms and specialties related to Information Systems (IS) and Information Technology (IT). The abduction process has more theoretical development than practical in relation to the integration of abduction and induction [8]. Other works consider digital interaction's abduction paradigm to be a research paradigm [23] and [24].

To solve the problems of single-case research, the approach based on the systematic combination in an abductive logic was implemented to improve theory development [25]. Flach and Kakas [8] contributions to abductive reasoning included logic programming, machine learning, and artificial intelligence.

The theory development in software engineering combines mainly inductive and abductive aspects, which may initiate from both the practical and theoretical perspectives. For example, in the related work, the abductive approach is applied to software requirements [26] and software testing [27]. Osei-Bryson and Ngwenyama [28] explore and illustrate the use of IT in IS research to assist researchers in the testing of theories and developments through mining techniques [29], decision trees [30], or logical foundations [7].

\section{Research approach}

\subsection{The result: data collection and evaluation}

This research study contains a group of apps that focuses on the needs of people with an intellectual disability who were assessed applying a specialized evaluation tool. The data collection contains some components and processes, which are following described.

Peer] Comput. Sci. reviewing PDF | (CS-2021:02:58241:1:0:NEW 14 May 2021) 
159

160

161

162

163

164

165

166

167

168

169

170

171

172

173

174

175

176

177

178

179

180

181

182

183

184

185

186

187

188

189

190

191

192

193

194

195

\subsubsection{The MARS tool}

As Holzinger et al. [31] determine, metric-based reference points are significant for quantifying software program usability, particularly for specific end-user groups. One of the principal qualities is its usability, as it is an indispensable feature of all software. It is even more crucial in apps created for a large range of users. Additionally, the requirements of people with disabilities are ruled out in the basic needs extraction procedure [32]. The fundamental elements of software-based clinical systems are; software apps measurement, quality assurance, and end-user satisfaction [33].

MARS is rated as an outstanding quality tool for efficient use for mobile health apps, developed from a methodical literature search to determine apps quality criteria [13]. MARS is a wellestablished tool worldwide that has been consulted by 201436 academics, cited by 526 researchers, and 78 tweets.

MARS scale assesses app quality on four dimensions, with similar grading to the Likert scale, e.g., "1. Inadequate" to "5. Excellent", 18 questions and descriptors were used [13]:

- Engagement: entertainment, interest, customization, interactivity, and target group.

- Functionality: performance, ease of use, navigation, and gestural design.

- Aesthetics: layout, graphics, and visual appeal.

- Information: accuracy of app description, goals, quality of information, the quantity of information, visual information, and credibility.

Table 1 shows the most relevant studies that use MARS. Selected articles use MARS to evaluate different types of apps in the health field.

Table 1: Related investigations.

\subsubsection{Apps collection}

In order to obtain accurate results, a relevant issue is the determination of the number of apps sampled and apps evaluated. Exploratory activity was performed doing a data compilation of web and mobile apps for people with disabilities using information from the year 2000 to 2020 . Figure 2 present the available data and showing the exponential growth of the number of apps in the period. Besides, the data universe size suggests that a good selection is a census of a specified domain for specific users and downloaded in an "instant" period.

Figure 2: Number of web and mobile apps published between 2000 and 2020.

The present research makes use of the Preferred Reporting Items for Systematic Reviews and Meta-Analyses tool (PRISMA) [34] o select the appropriate apps for testing in the MARS tool. PRISMA [35] consists in a four-phase flowchart: identification, screening, eligibility, and inclusion. The apps were selected on different platforms. Table 2 illustrates the search and inclusion process conditions.

Table 2: Search process. 
196 The researchers chose the apps across four platforms: desktop $22.83 \%$, web $33.45 \%$, Android

197

198

199

200

201

202

203

204

205

206

207

208

209

210

211

212

213

214

215

216

217

218

219

220

221

222

223

224

225

226

227

228

229

230

231

$22.12 \%$, and iOS $21.59 \%$.

\subsubsection{Apps evaluation}

There are three stakeholder groups to assess apps for people with disabilities: health specialists, software specialists, and final users. The initial approach used a sample of four apps which teachers, software testers, and children with disabilities evaluated. A group of 10 specialized teachers for people with disabilities, 15 children with special educational needs or intellectual disabilities, and five software testers used MARS to evaluate the apps.

The authors created a new Spanish version based on the MARS template. Still, due to the questionnaire's size and complexity, it was necessary to adapt it for children with disabilities and test it. Although the results of the teachers' and children's evaluations of the apps were similar, the software testers' evaluation shows some discrepancies, as shown in Figure 3.

Figure 3: Joint assessment of four apps for people with disabilities

The complete test series included a total of 1125 apps after a PRISMA screening process deleted duplicates and non-available apps, having a result of 565 apps, where 123 iOS apps, 125 Android apps, 190 web apps, and 127 Windows apps to be evaluated with MARS. Two independent software testers performed the evaluation. Table 3 shows the devices used to complete the assessment.

Table 3: Devices used for evaluation.

Table 4 contains data extracted from evaluated apps and displays a summary of 10 random apps: original MARS score, competitive classification group, and new MARS score. The competitive classification group is defined by a competitive neural network applied to MARS data. The new MARS score is the average of the most significant MARS items (X2, X5, X6, X8, X11, X15) given by a greedy stepwise algorithm.

Table 4: Data extracted from the apps evaluated.

\subsubsection{Interpretation of the results}

Cronbach's $\alpha$ is the most useful as a positive test to determine an instrument's internal consistency [36]. An appropriate reliability score is one of 0.7 or higher [37]. In this case, the value is 0.966 ; but this value suggests there are data item duplications. Table 5 shows the data regression matrix corresponding to categorical variables and a high linear correlation between some of them; this result can also be related to data item duplications. The gray cells show the values which have a higher correlation between the variables; higher values are considered greater than 0.5 .

Table 5: Data regression matrix. 
232 The most significant descriptive statistical results between the non-linear distribution of the

233 variables and the direct proportional relationships are shown in Figure 4. The non-linear

234 distributions are the consequence of the categorical variables of the Likert scale used in MARS.

235 The positive proportional relationship between all variables shows that the feedback was $100 \%$

236 positive. This effect would be a strange result only possible in inexistent open systems, where the 237 possible improvements are limitless.

Figure 4: Scatter plot matrix for the first nine variables.

239

240

241

242

243

244

245

246

247

248

249

250

251

252

253

254

255

256

257

258

259

260

261

262

263

264

265

266

267

268

269

Summarizing the previous facts: 1) The high linear correlations suggest that some variables introduce duplications in data; 2) The distribution of categorical variable values are non-linear; therefore, possible models for treating the data must support non-linear data; 3) Considering the perspective of the MARS results, the tool defines a quality value of apps that is ultimately accepted and not guide apps' quality measurement and interpretation process satisfactorily. As MARS was systematically defined, it is insufficient to understand the ratings. Therefore, theorizing and applying a technique to reduce MARS factors is a feasible research objective to utilize abductive reasoning.

\subsection{The rule: the new explanatory model}

A variable is represented by a feature that is a specific quantifiable property of a procedure being observed. Feature selection assists in the comprehension of data, reducing computer skill requirement, simplifying dimensionality, and improving the predictor performance.

Subsequently, the focus of feature selection is to choose a subset of input variables that can explain data, limiting the impacts from noise or superfluous variables, and still provide an improved selection of predictive results [10], [11], [12].

Label information is the feature selection technique classified into three groups: supervised methods, semi-supervised methods, and unsupervised methods [38], [39], [40]. Label information enables the supervised feature selection algorithms to effectively opt for discriminative and pertinent features, to highlight samples from different classes.

Feature selection is also classified into three techniques: filter, wrapper, and embedded methods [11], [12], [38]. The filter models are fast and straightforward, while the embedded methods trend to performance optimization manages high data volume. The wrapper methods achieve balance.

Wrapper methods incorporate a learning algorithm, similar to a black box, and consist of utilizing the prediction performance to evaluate the relative feature of subsets of variables. Alternatively, the feature selection algorithm applies a learning method (Classifier) as a subroutine with the computational load that originates from taking a learning algorithm to assess each subset of features [41], [42] (See Figure 5).

Figure 5: Wrapper method configuration. (Adapted from Bolón-Canedo et al. [42]) 
270 Guyon analyzed the use of criteria techniques to select features: the objective function, feature

271 construction, feature ranking, multivariate feature selection, efficient search methods, and feature

272 validity assessment methods [10]. Chosen options for Feature Selection are Wrapper Subset

273 Evaluator, Correlation-based Feature Subset Selection (CFS), Principal Components Analysis,

274 [43], [44], [45]. Other options for Search Methods (Classifiers) are Greedy Stepwise and Best

275 First [11], [46].

276 In this research, it is essential to recognize that the data variables are discrete and non-linear,

277 creating limitations. Therefore, options of Feature Selection are CFS and Wrapper Subset

278 Evaluator. Wrapper Subset Evaluator are techniques based on Bayes, Rules, Functions, and

279 Trees, as can be studied in the works of Abusamra [43], Kaur et al. [44], and Karabulut et al.

280 [45].

281 Figure 6 illustrates the current data collection evidence that the MARS score, a mean value, is an

282 apparent dependent variable that can be deleted without changing the data. In this case, an option

283 is to use an unsupervised learning technique to re-classify the results. It is possible to filter the

284 relevance of the variables utilizing a wrapper feature selection technique. At last, the software

285 quality elements are pinpointed and interpreted.

286

287

Figure 6: The model to identify relevant quality factors.

\section{3.3. The case}

289

290

291

292

293

294

295

296

297

298

299

300

301

302

303

304

305

306

307

308

In order to apply the new model for the apps, it is essential to use one unsupervised classifier, a supervised wrapper, and a search technique. The classifier in this research study implemented a self-organizing connect with a competitive network version, able to determine consistencies and correlations in their input and adapt their future output [47].

In an initial assessment, utilizing the Merit as an efficiency measure [48], the optimum results were revealed by Multilayer Perceptron as a wrapper method and greedy stepwise as a search technique.

Merit is calculated as:

$$
M_{S}=\frac{k \overline{r_{c f}}}{\sqrt{k+k(k-1) \overline{r_{f f}}}}
$$

where the heuristic "Merit" of a feature subset $\mathrm{S}$ containing $\mathrm{k}$ features, $r_{c f}$ is the mean featureclass correlation $(f \in S)$, and $r_{f f}$ is the average feature-feature intercorrelation.

The numerator of the equation illustrates how predictive of the class a set of characteristics is, the denominator of how many of them are redundant. Consequently, the higher value of $M_{S}$ means better data classification.

\subsubsection{Self-organizing neural network}

The neurons of self-organizing maps learn to identify groups of comparable input vectors to ensure that neurons physically near each other in the neuron layer respond to identical input vectors [49]. The competitive learning models, a type of self-organizing maps, are based upon 
309

310

311

312

313

314

315

316

317

318

319

320

321

322

323

324

325

326

327

328

329

330

331

332

333

334

335

336

337

338

339

340

341

342

the principle of Winner Take All, specified as the closest weight vector to the existing input vector [38]. The formula to discover the winning neuron, $i(t)$, is:

$$
i(t)=\arg \min _{\forall i}\|x(t)-W i(t)\|
$$

Where $x(t)$ is the current input vector, $w_{i}(t)$ is the weight vector of neuron $\mathrm{i}$, and $\mathrm{t}$ is the iteration number. The weight vector of the winning neuron is iteratively modified, using a learning rate $\eta(0 \leq \eta \leq 1)$, through [38]: Where $x(t)$ is the current input vector, $w_{i}(t)$ is the weight vector of neuron $i$, and $t$ is the iteration number. The weight vector of the winning neuron is iteratively modified, using a learning rate $\eta(0 \leq \eta \leq 1)$, through [10]:

$$
w_{i}(t+1)=w_{i}(t)+\eta\left[x(t)-w_{i}(t)\right]
$$

\subsubsection{Greedy stepwise search method}

The greedy stepwise executes a greedy forward or backward search through the area of characteristic subsets; the process finalizes when the addition/subtraction of any remaining feature causes a lesser evaluation. The method, described by Arguello [50], solves the following model based on the Variance:

$$
\begin{gathered}
\max _{S \subset P} R^{2}(G, S) \\
\text { s. } t .|S|=k
\end{gathered}
$$

Where $\mathrm{K}$ is the number of data sources to choose, $\mathrm{P}$ is the data sources, $\mathrm{G}$ is the target data, and $\alpha_{i}$ are the regression coefficients from fitting $\mathrm{G}$ using the $P_{i}$ 's

$$
R^{2}(G, S)=\frac{\operatorname{Var}(G)-\operatorname{Var}\left(G-\sum_{i \in S} \alpha_{i} P_{i}\right)}{\operatorname{Var}(G)}
$$

\subsubsection{Multilayer perceptron}

A supervised classification was building a class model from a set of records containing class labels [51]. A multilayer perceptron (MLP), a class of feedforward artificial neural network, categorizes data that is not linearly separable.

An MLP contains a minimum of three layers of nodes: an input layer, a concealed layer, and an outcome layer. Besides the input nodes, each node is a neuron that uses a non-linear activation feature. MLP applies a supervised learning method, backpropagation, for training. Its numerous layers and non-linear activation differentiate MLP from a linear perceptron. MLP is formalized by:

$$
y=h(A)=h(g(I))=h\left(g\left(f\left(\sum X_{p i} \times W_{j i}\right)\right)\right)
$$

Where $X_{p i}$ is the input vector of dimension $\mathrm{p}$; $\mathrm{f}$ is the input function; $\mathrm{g}$ is the activation function, and $\mathrm{h}$ represents the training function. Weights $W_{j i}$ are updated using a backpropagation process. 
343

344

345

346

347

348

349

350

351

352

353

354

355

356

357

358

359

360

361

362

363

364

365

366

367

368

369

370

371

372

373

374

375

376

377

378

379

380

381

382

383

\subsubsection{Model application and results}

According to the process specified in Figure 4, the application's details and results are documented. The MARS output data are categorized by the competitive model (see Figure 7). Four is the logical number of categories that coincides with the number of Mars categories.

Figure 7: Competitive neural network architecture used for data classification.

Table 6 displays a summary of the classification results, the best of several attempts in each one, which is improved by trial-and-error technique until the response was stable. Different combinations of the learning rate, initial weights, and iterations are examined; in addition, the Merit value is considered, according to the explanation below. MATLAB's nntool, with 500 epochs and a learning scale of 0.1 was applied for data processing.

Table 6: Summary of the cases classification.

The results show that the MARS score and the competitive classification are not necessarily similar (See Figure 8 and Table 4). This fact can be interpreted as the way the MARS tool users understand the model's questions in a particular form for each app since the mean value assumes the same interpretation in all app cases.

Figure 8: MARS evaluation values and Competitive Classification.

The classified data is applied to choose the relevant variables with the greedy stepwise algorithm as a search method and J48, an extension of ID3 and C4.5, as a classifier. The combination was run as a wrapper method in Weka [52] [53].

The value of Merit (MS) of the feature selection [52] was 1.024. The algorithms produce as selected attributes the variables X2, X5, X6, X8, X11, X15 as relevant for the study. Using the chosen variables, it is possible to recalculate the MARS quality score (See Table 4, for example, Figure 9). There is a similitude on the tendency of the value.

Figure 9: Old and new MARS scores of apps.

The results of competitive classification can be useful to select apps of similar quality. Each app case requires an individual analysis; for example, the competitive classification in a group of apps Blindfold sudoku and Memora - classic (See Table 4) is identical, despite the original MARS scores are different. In another case, the competitive classification can be different, although the original MARS scores are similar. The competitive trained model can also be used to classify a MARS evaluation of a new app and identify others of similar quality.

Finally, the group of six selected variables proves the following:

1. The four MARS categories are maintained, but some subcategories are optional.

2. The interest and target group represent the engagement category.

3. Performance and navigation represent the functionality category.

Peer] Comput. Sci. reviewing PDF | (CS-2021:02:58241:1:0:NEW 14 May 2021) 
384

385

386

387

388

389

390

391

392

393

394

395

396

397

398

399

400

401

402

403

404

405

406

407

408

409

410

411

412

413

414

415

416

417

418

419

420

421

422

423

4. Graphics represent the aesthetics category.

5. The quality of information is defined as the information category.

\section{Discussion}

The use of the abductive process to theory generation is summarized in Figure 10. Initially, the result has an old hypothesis: The Apps quality evaluation, using the MARS tool, facilitates the complete identification and interpretation of quality factors. In this phase, the MARS tool is used considering the practices applied in relevant research and recommended by the tool's authors.

After obtaining the MARS evaluation values, a disruption is identified from the use quality [54]. Although the MARS tool was created using a systematic process, its application shows average values and a set of descriptive statistical values, which do not permit new explanations and interpretations about the apps' quality factors.

Figure 10: Abductive reasoning process used in this research. The abductive reasoning process (left). The hypotheses and the application process of the new model (right).

As such, a new rule or model is necessary. The following is the new hypothesis: The results of apps' quality evaluation enable selecting quality features, using data mining techniques ordered in a new processing model. In this phase, the MARS tool results are processed using a new model to obtain the relevant quality factors. A case is defined and developed; that is, the new rule is applied to the original MARS evaluation results, generating further explanations and interpretations of the old results. The new findings have useful evidence about their validity. As is noted in the data collection, the data corresponding to one evaluation per app, and the group have a domain related to people with disabilities, which run on similar technological platforms (mobiles). These facts can be interpreted as the data capture the generalized quality of apps in the specified domain and specific users. Collaterally, the classification obtained of the competitive neural network enables to identify of the classification group and the apps with similar quality.

Feature selection process identifies six relevant variables, and according to Chandrashekar and Sahin [11], which assists with the interpretation of data, minimizing the effect of the dimensionality, and increasing the predictor performance.

Reducing dimensionality permits a better understanding of the quality factors. In this way, the components of a quality profile for apps for people with disabilities are settings, interactions, goals, and information. This profile can be used as a criterion for apps quality improvement. In this research, reducing the computation requirement is not an objective because of the data size. But the possibility of the use the selected variables to construct a small questionnaire directed to final users and specialists is an essential output of the new explanation. The result constitutes an improvement to the predictor performance. It can be recognized as a significant outcome, which would contribute to react adequately to the dynamics of the current context of development and the massive emergence of mobile Apps. 
424 In many data mining machine learning applications, the precise knowledge structures are 425 acquired, the structural descriptions are equally as important as the ability to perform well on 426 new examples [55]. Also, researchers regularly use data mining to extract knowledge, not only 427 predictions [52]. Both opinions support the idea of a theory generation, according to the 428 assertions of Horváth [3] and Wacker [4] considered in the related work of this study. 429 The contents of this study identify the collected data as MARS application results (what), 430 describe (how), and explain (why) their significance, based on a new quantitative model. 431 Similarly, the study establishes the conditions for the new model (when and where). Therefore, 432 according to Recker [56], cited in the related work, the experience described in this study 433 reached the generation of an explanatory theory.

\section{Conclusions and future work}

435 The post-positivist philosophies of social science have identified the basic restrictions of the 436 positivist behavioral approach to IS research study and present new goals for the systematic 437 development of scientific research practice. Therefore, further research is of the utmost 438 importance [57].

439 The abductive approach has been used in IS domains; as well as the multiple options to use 440 quantitative techniques are considered and potentiate the results. The application is also related 441 to apps quality using data mining techniques and evidence a practical use case; an initial 442 quantitative model is analyzed using other specialized quantitative models.

443 The investigative community has generated several qualitative and quantitative models in varied 444 domains, like MARS. So, the general concepts of this work are applicable because the used 445 process constitutes an assessment of the proposed model's external consistency (Rule); that is, 446 according to Brown [58] and the outer reliability enhanced/verified by inspecting statistical 447 results regarding process replication.

448 The main contribution of this work is to decrease from 18 to 6 items of the MARS to evaluate 449 apps; those selected attribute the variables X2, X5, X6, X8, X11, X15 as relevant to the study. 450 This reduction in the number of variables reduces the time needed to evaluate the quality of an 451 app since fewer items are needed, but without a decrease in the quality of the results.

452 Of the investigations mentioned, the evaluators are health specialists and the article's authors.

453 Only in the previous research, the app's evaluation was carried out by final users, a cancer

454 survivors' group. A research opportunity exists to expand the coverage of assessment, 455 considering the users with disabilities.

456 In the present research, it is possible to stimulate suggestions for improvement and study the 457 validity of generalizations, starting with machine learning for data mining.

458 The experience results contribute to new quantitative possibilities, such as using other intelligent 459 options and multivariate statistical techniques to identify factors of new domains, not necessarily 460 including feature selection. Alike, simulation models can be utile to experiment with various 461 scenarios and identifying transcendental quality factors.

462 A pending research theme related to the experience presented here is the stakeholders' 463 participation in the apps evaluation process. Based on the preliminary evidence described, the 
464

465

466

467

468

470

471

472

473

474

475

476

477

478

479

480

481

482

483

484

485

486

487

488

489

490

491

492

493

494

495

496

497

498

499

500

501

502

503

504

505

506

507

results of this research are invaluable. Additionally, comparative studies could be beneficial for the final user and specialists' involvement.

With this research, academics can revise a new experience using an alternative reasoning process to overcome IS research's positivism. For the practitioners, the study contributes to the growth of the current knowledge about apps quality assessment related to people with disabilities.

\section{References}

[1] D. Sjøberg, T. Dybå, B. Anda, J. Hannay, Building Theories in Software Engineering, in: F. Shull, J. Singer, D. Sjøberg (Eds.), Guide to Advanced Empirical Software Engineering, Springer London, London, 2008: pp. 312-336. https://doi.org/10.1007/978-1-84800-0445_12.

[2] K. Corley, D. Gioia, Building theory about theory building: what constitutes a theoretical contribution?, Academy of Management Review. (2011) 21.

[3] I. Horváth, Theory Building in Experimental Design Research, in: P. Cash, T. Stanković, M. Štorga (Eds.), Experimental Design Research, Springer International Publishing, Cham, 2016: pp. 209-231. https://doi.org/10.1007/978-3-319-33781-4_12.

[4] J. Wacker, A definition of theory: research guidelines for different theory-building research methods in operations management, Journal of Operations Management. 16 (1998) 361385. https://doi.org/10.1016/S0272-6963(98)00019-9.

[5] A. Aliseda, Abductive reasoning: logical investigations into discovery and explanation, Springer, Dordrecht, The Netherlands, 2006.

[6] K. Philipsen, Theory Building: Using Abductive Search Strategies, in: P.V. Freytag, L. Young (Eds.), Collaborative Research Design, Springer Singapore, Singapore, 2018: pp. 45-71. https://doi.org/10.1007/978-981-10-5008-4_3.

[7] O. Ngwenyama, Logical Foundations of Social Science Research, in: K.-M. Osei-Bryson, O. Ngwenyama (Eds.), Advances in Research Methods for Information Systems Research: Data Mining, Data Envelopment Analysis, Value Focused Thinking, Springer US, Boston, MA, 2014: pp. 7-13. https://doi.org/10.1007/978-1-4614-9463-8_2.

[8] P. Flach, A. Kakas, Abductive and Inductive Reasoning: Background and Issues, in: P. Flach, A. Kakas (Eds.), Abduction and Induction, Springer Netherlands, Dordrecht, 2000: pp. 1-27. https://doi.org/10.1007/978-94-017-0606-3_1.

[9] T. Kapitan, Peirce and the autonomy of abductive reasoning, Erkenntnis. 37 (1992). https://doi.org/10.1007/BF00220630.

[10] I. Guyon, A. Elisseeff, An Introduction to Variable and Feature Selection, (2003) 26.

[11] G. Chandrashekar, F. Sahin, A survey on feature selection methods, Computers \& Electrical $\quad$ Engineering. $\quad 40 \quad$ (2014) https://doi.org/10.1016/j.compeleceng.2013.11.024.

[12] Y. Saeys, I. Inza, P. Larranaga, A review of feature selection techniques in bioinformatics, Bioinformatics. 23 (2007) 2507-2517. https://doi.org/10.1093/bioinformatics/btm344.

[13] S. Stoyanov, L. Hides, D. Kavanagh, O. Zelenko, D. Tjondronegoro, M. Mani, Mobile App Rating Scale: A New Tool for Assessing the Quality of Health Mobile Apps, JMIR MHealth and UHealth. 3 (2015) e27. https://doi.org/10.2196/mhealth.3422.

[14] C. O'Reilly, Creative Engineers: Is Abductive Reasoning Encouraged enough in Degree Project Work?, Procedia CIRP. $50 \quad$ (2016) 547-552. https://doi.org/10.1016/j.procir.2016.04.155. 
508

509

510

511

512

513

514

515

516

517

518

519

520

521

522

523

524

525

526

527

528

529

530

531

532

533

534

535

536

537

538

539

540

541

542

543

544

545

546

547

548

549

550

551

552

553

[15] A. Aliseda, The Logic of A 10. The Logic of Abduction: An Introduction, in: Springer Handbook of Model-Based Science, 2017: p. 12. https://doi.org/10.1007/978-3-319-305264.

[16] J. Olsen, A. Gjerding, Modalities of Abduction: a Philosophy of Science-Based Investigation of Abduction, Hu Arenas. 2 (2019) 129-152. https://doi.org/10.1007/s42087018-0044-4.

[17] D. Żelechowska, N. Żyluk, M. Urbański, Find Out A New Method to Study Abductive Reasoning in Empirical Research, International Journal of Qualitative Methods. 19 (2020) 160940692090967. https://doi.org/10.1177/1609406920909674.

[18] C. Rapanta, Teaching as Abductive Reasoning: The Role of Argumentation, IL. 38 (2018) 293-311. https://doi.org/10.22329/il.v38i2.4849.

[19] A. Mitchell, A Review of Mixed Methods, Pragmatism and Abduction Techniques, 16 (2018) 14.

[20] A. Fariha, A. Meliou, Example-Driven Query Intent Discovery: Abductive Reasoning using Semantic Similarity, ArXiv:1906.10322 [Cs]. (2019). http://arxiv.org/abs/1906.10322.

[21] A. Ganesan, P. Parameshwarappa, A. Peshave, Z. Chen, T. Oates, Extending Signaturebased Intrusion Detection Systems WithBayesian Abductive Reasoning, ArXiv:1903.12101 [Cs]. (2019). http://arxiv.org/abs/1903.12101.

[22] C. Bhagavatula, R.L. Bras, C. Malaviya, K. Sakaguchi, A. Holtzman, H. Rashkin, D. Downey, S.W. Yih, Y. Choi, Abductive Commonsense Reasoning, ArXiv:1908.05739 [Cs]. (2020). http://arxiv.org/abs/1908.05739.

[23] E. Patokorpi, Role of abductive reasoning, Åbo Akademi University, 2006.

[24] E. Patokorpi, M. Ahvenainen, Developing an abduction-based method for futures research, Futures. 41 (2009) 126-139. https://doi.org/10.1016/j.futures.2008.09.019.

[25] A. Dubois, L.-E. Gadde, Systematic combining: an abductive approach to case research, Journal of Business Research. 55 (2002) 553-560. https://doi.org/10.1016/S01482963(00)00195-8.

[26] A. d'Avila Garcez, A. Russo, B. Nuseibeh, J. Kramer, Combining abductive reasoning and inductive learning to evolve requirements specifications, IEE Proceedings - Software. 150 (2003) 25. https://doi.org/10.1049/ip-sen:20030207.

[27] N. Angius, Model-based abductive reasoning in automated software testing, Logic Journal of IGPL. 21 (2013) 931-942. https://doi.org/10.1093/jigpal/jzt006.

[28] K.-M. Osei-Bryson, O. Ngwenyama, Advances in Research Methods for Information Systems Research: Data Mining, Data Envelopment Analysis, Value Focused Thinking, Springer Science \& Business Media, 2013.

[29] K.-M. Osei-Bryson, O. Ngwenyama, An Approach for Using Data Mining to Support Theory Development, in: K.-M. Osei-Bryson, O. Ngwenyama (Eds.), Advances in Research Methods for Information Systems Research, Springer US, Boston, MA, 2014: pp. 23-43. https://doi.org/10.1007/978-1-4614-9463-8_4.

[30] K.-M. Osei-Bryson, O. Ngwenyama, Using decision tree modelling to support Peircian abduction in IS research: a systematic approach for generating and evaluating hypotheses for systematic theory development: Using decision tree modelling, Information Systems Journal. 21 (2011) 407-440. https://doi.org/10.1111/j.1365-2575.2010.00368.x.

[31] A. Holzinger, G. Searle, T. Kleinberger, A. Seffah, H. Javahery, Investigating Usability Metrics for the Design and Development of Applications for the Elderly, in: K. Miesenberger, J. Klaus, W. Zagler, A. Karshmer (Eds.), Computers Helping People with

Peer) Comput. Sci. reviewing PDF | (CS-2021:02:58241:1:0:NEW 14 May 2021) 
554

555

556

557

558

559

560

561

562

563

564

565

566

567

568

569

570

571

572

573

574

575

576

577

578

579

580

581

582

583

584

585

586

587

588

589

590

591

592

593

594

595

596

597

598

599

Special Needs, Springer Berlin Heidelberg, Berlin, Heidelberg, 2008: pp. 98-105. https://doi.org/10.1007/978-3-540-70540-6_13.

[32] H. Guerrero, V. Vega, Usability analysis: Is our software inclusive?, in: J. Mejia, M. Muñoz, Á. Rocha, Y. Quiñonez, J. Calvo-Manzano (Eds.), Trends and Applications in Software Engineering, Springer International Publishing, Cham, 2018: pp. 221-230. https://doi.org/10.1007/978-3-319-69341-5_20.

[33] N. Ahamed, K. Sundaraj, B. Ahmad, M. Rahman, A. Ali, A Framework for the Development of Measurement and Quality Assurance in Software-Based Medical Rehabilitation Systems, Procedia Engineering. 41 (2012) 53-60.

[34] A. Liberati, D.G. Altman, J. Tetzlaff, C. Mulrow, P.C. Gotzsche, J.P.A. Ioannidis, M. Clarke, P.J. Devereaux, J. Kleijnen, D. Moher, The PRISMA statement for reporting systematic reviews and meta-analyses of studies that evaluate healthcare interventions: explanation and elaboration, BMJ. 339 (2009) b2700-b2700.

[35] B. Hutton, G. Salanti, D.M. Caldwell, A. Chaimani, C.H. Schmid, C. Cameron, J.P.A. Ioannidis, S. Straus, K. Thorlund, J.P. Jansen, C. Mulrow, F. Catalá-López, P.C. Gøtzsche, K. Dickersin, I. Boutron, D.G. Altman, D. Moher, The PRISMA Extension Statement for Reporting of Systematic Reviews Incorporating Network Meta-analyses of Health Care Interventions: Checklist and Explanations, Annals of Internal Medicine. 162 (2015) 777. https://doi.org/10.7326/M14-2385.

[36] D. Straub, D. Gefen, Validation Guidelines for IS Positivist Research, Communications of the Association for Information Systems. 13 (2004). https://doi.org/10.17705/1CAIS.01324.

[37] R. Heale, A. Twycross, Validity and reliability in quantitative studies, Evidence Based Nursing. 18 (2015) 66-67.

[38] J. Miao, L. Niu, A Survey on Feature Selection, Procedia Computer Science. 91 (2016) 919-926. https://doi.org/10.1016/j.procs.2016.07.111.

[39] J. Dy, C. Brodley, Feature Selection for Unsupervised Learning, (2004) 45.

[40] M. Law, M. Figueiredo, A. Jain, Simultaneous feature selection and clustering using mixture models, IEEE Transactions on Pattern Analysis and Machine Intelligence. 26 (2004) 1154-1166. https://doi.org/10.1109/TPAMI.2004.71.

[41] R. Kohavi, G. John, Wrappers for feature subset selection, Artificial Intelligence. 97 (1997) 273-324. https://doi.org/10.1016/S0004-3702(97)00043-X.

[42] V. Bolón-Canedo, N. Sánchez-Maroño, A. Alonso-Betanzos, Feature selection for highdimensional data, Progress in Artificial Intelligence. 5 (2016) 65-75. https://doi.org/10.1007/s13748-015-0080-y.

[43] H. Abusamra, A Comparative Study of Feature Selection and Classification Methods for Gene Expression Data of Glioma, Procedia Computer Science. 23 (2013) 5-14. https://doi.org/10.1016/j.procs.2013.10.003.

[44] R. Kaur, Study and Comparison of Feature Selection Approaches for Intrusion Detection, International Journal of Computer Applications. (2016) 7.

[45] E. Karabulut, S. Özel, T. İbrikçi, A comparative study on the effect of feature selection on classification accuracy, Procedia Technology. 1 (2012) 323-327. https://doi.org/10.1016/j.protcy.2012.02.068.

[46] W. Punch, E. Goodman, M. Pei, L. Chia-Shun, P. Hovland, R. Enbody, Further Research on FGeaetnuerteicSAellegcotriiotnhmansd Classi cation Using, (1993) 8.

[47] A. Ukil, A. Ukil, Intelligent Systems and Signal Processing in Power Engineering, Springer Berlin Heidelberg, Berlin, Heidelberg, 2007. https://doi.org/10.1007/978-3-540-73170-2. 
600 [48] M. Hall, Correlation-based Feature Selection for Machine Learning, (1999) 198.

601 [49] H. Akbari, Y. Kosugi, K. Kojima, N. Tanaka, Wavelet-Based Compression and

602

603

604

605

606

607

608

609

610

611

612

613

614

615

616

617

618

619

620

621

622

623

624 Segmentation of Hyperspectral Images in Surgery, in: T. Dohi, I. Sakuma, H. Liao (Eds.), Medical Imaging and Augmented Reality, Springer Berlin Heidelberg, Berlin, Heidelberg, 2008: pp. 142-149. https://doi.org/10.1007/978-3-540-79982-5_16.

[50] B. Arguello, A Survey of Feature Selection Methods: Algorithms and Software, (2015) 39.

[51] S. Lotulitr', S. Romlee', S. Yumaneel, D.P. Phunchongharn', SPIN: A Web-Based Application for Exploring Stored-Product Insects, (2016) 4.

[52] I. Witten, E. Frank, M. Hall, C. Pal, Data Mining: Practical Machine Learning Tools and Techniques, Elsevier, 2011. https://doi.org/10.1016/C2009-0-19715-5.

[53] R. Bouckaert, E. Frank, M. Hall, R. Kirkby, P. Reutemann, A. Seewald, D. Scuse, WekaManual-3-7-8.pdf, (2013).

[54] ISO, Systems and software engineering. Systems and software Quality Requirements and Evaluation (SQuaRE). Guide to SQuaRE:, BSI British Standards, n.d. https://doi.org/10.3403/30289026.

[55] R. Grainger, H. Townsley, B. White, T. Langlotz, W.J. Taylor, Apps for People With Rheumatoid Arthritis to Monitor Their Disease Activity: A Review of Apps for Best Practice and Quality, JMIR MHealth and UHealth. 5 (2017) e7.

[56] J. Recker, Scientific Research in Information Systems, Springer Berlin Heidelberg, Berlin, Heidelberg, 2013. https://doi.org/10.1007/978-3-642-30048-6.

[57] K.-M. Osei-Bryson, O. Ngwenyama, eds., Advances in Research Methods for Information Systems Research, Springer US, Boston, MA, 2014. https://doi.org/10.1007/978-1-46149463-8.

[58] J. Brown, Consistency in research design: Categories and subcategories, (2016) 6. 
Figure 1

Inference forms. (Adapted from Philipsen [6])

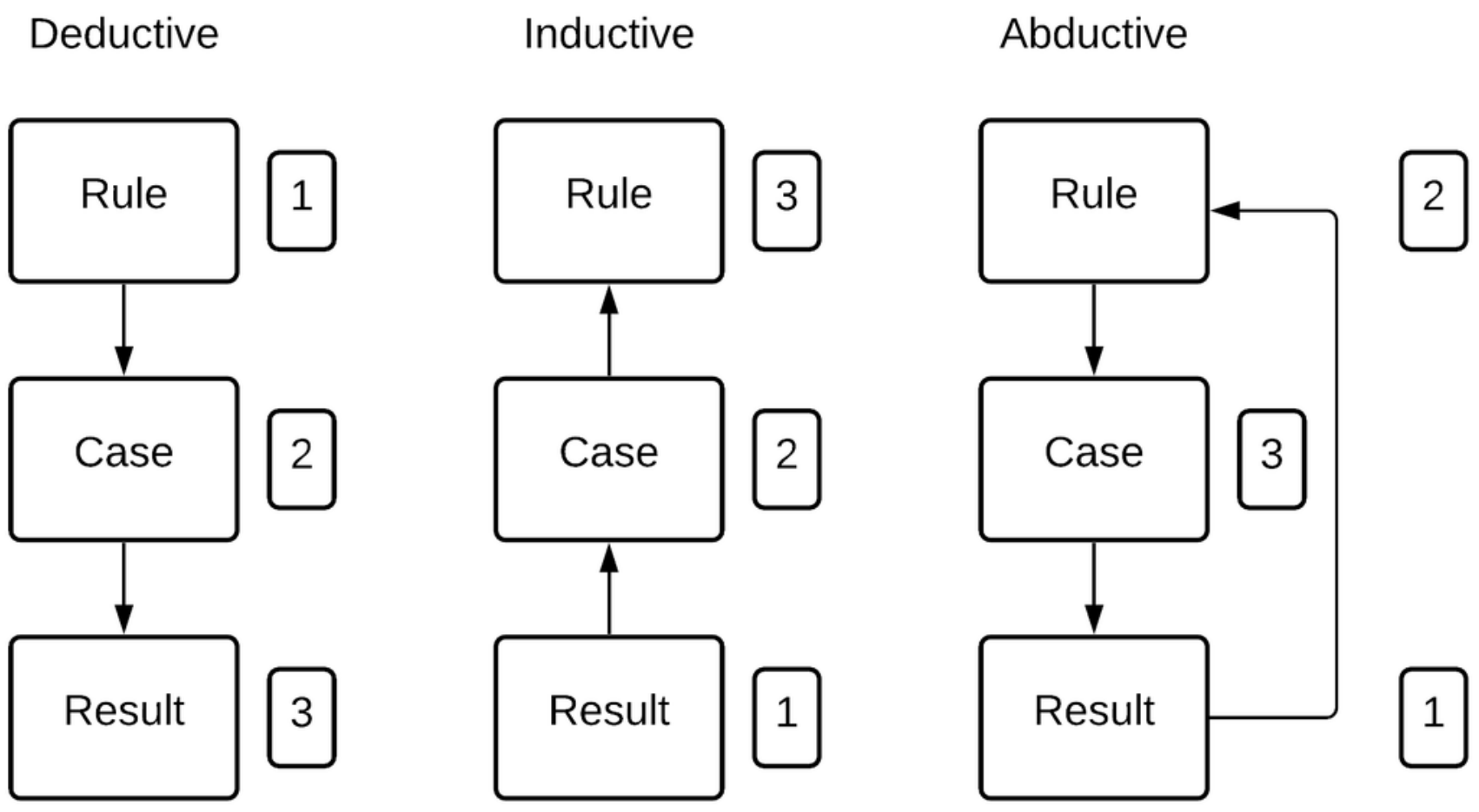


Figure 2

Number of web and mobile apps published between 2000 and 2020

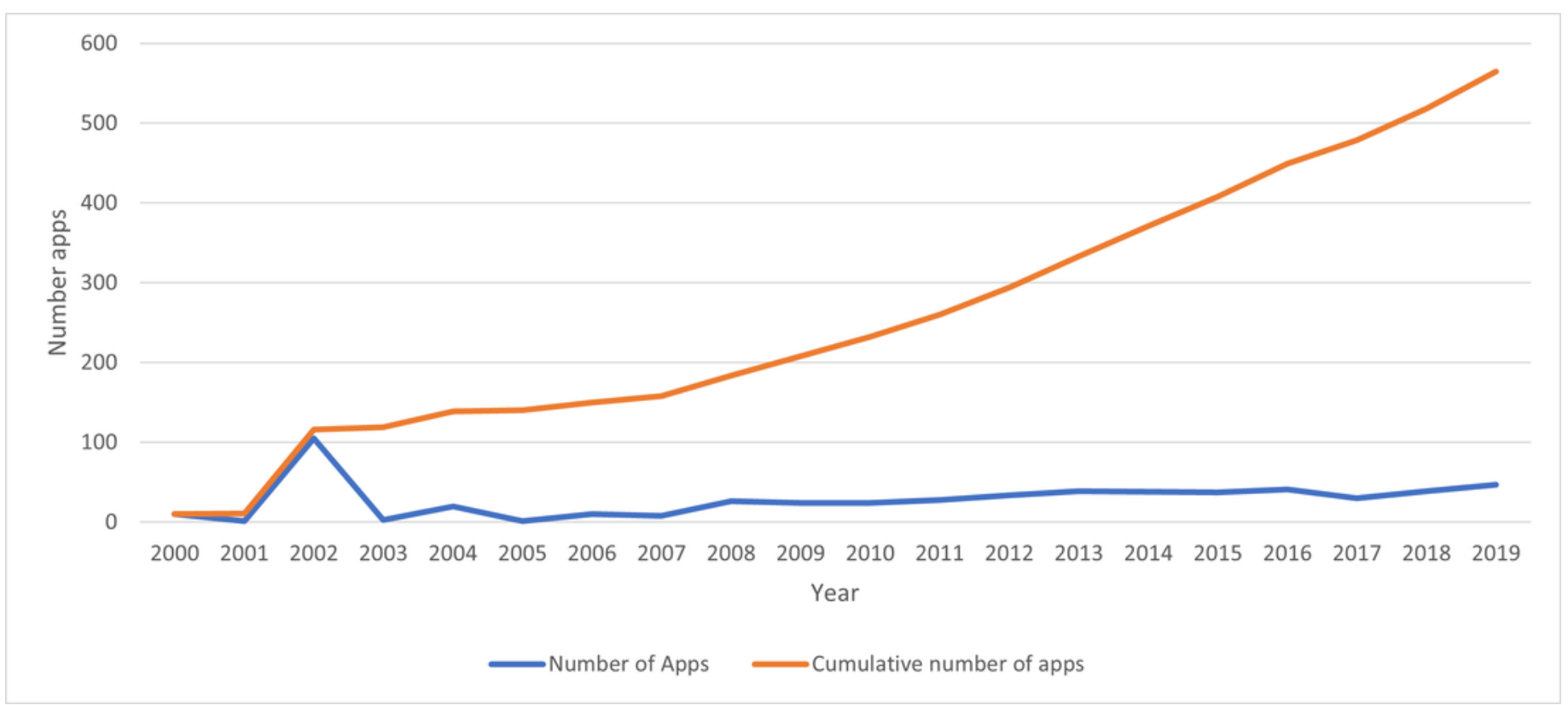


Figure 3

Joint assessment of four apps for people with disabilities

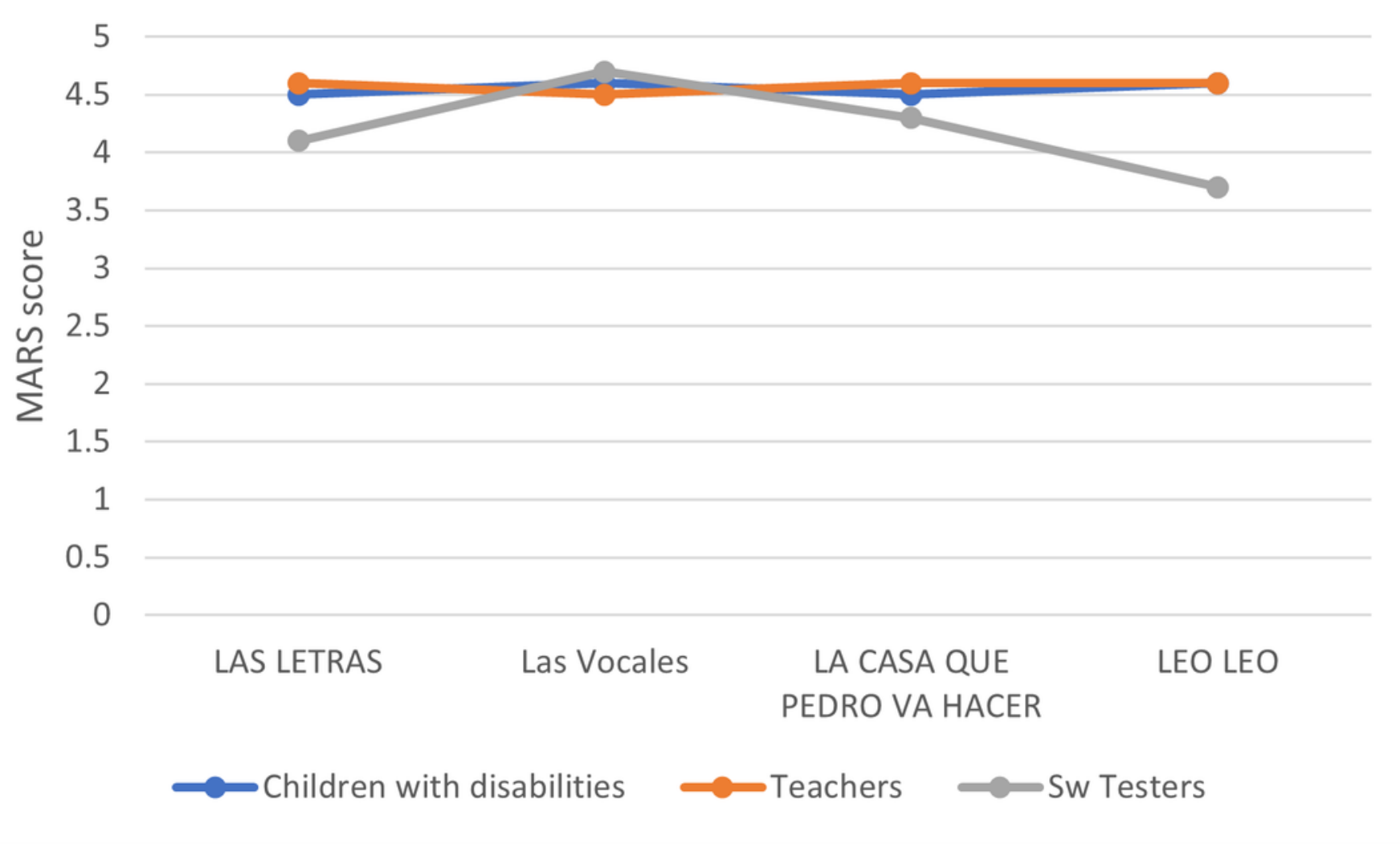


Figure 4

Scatter plot matrix for the first nine variables.

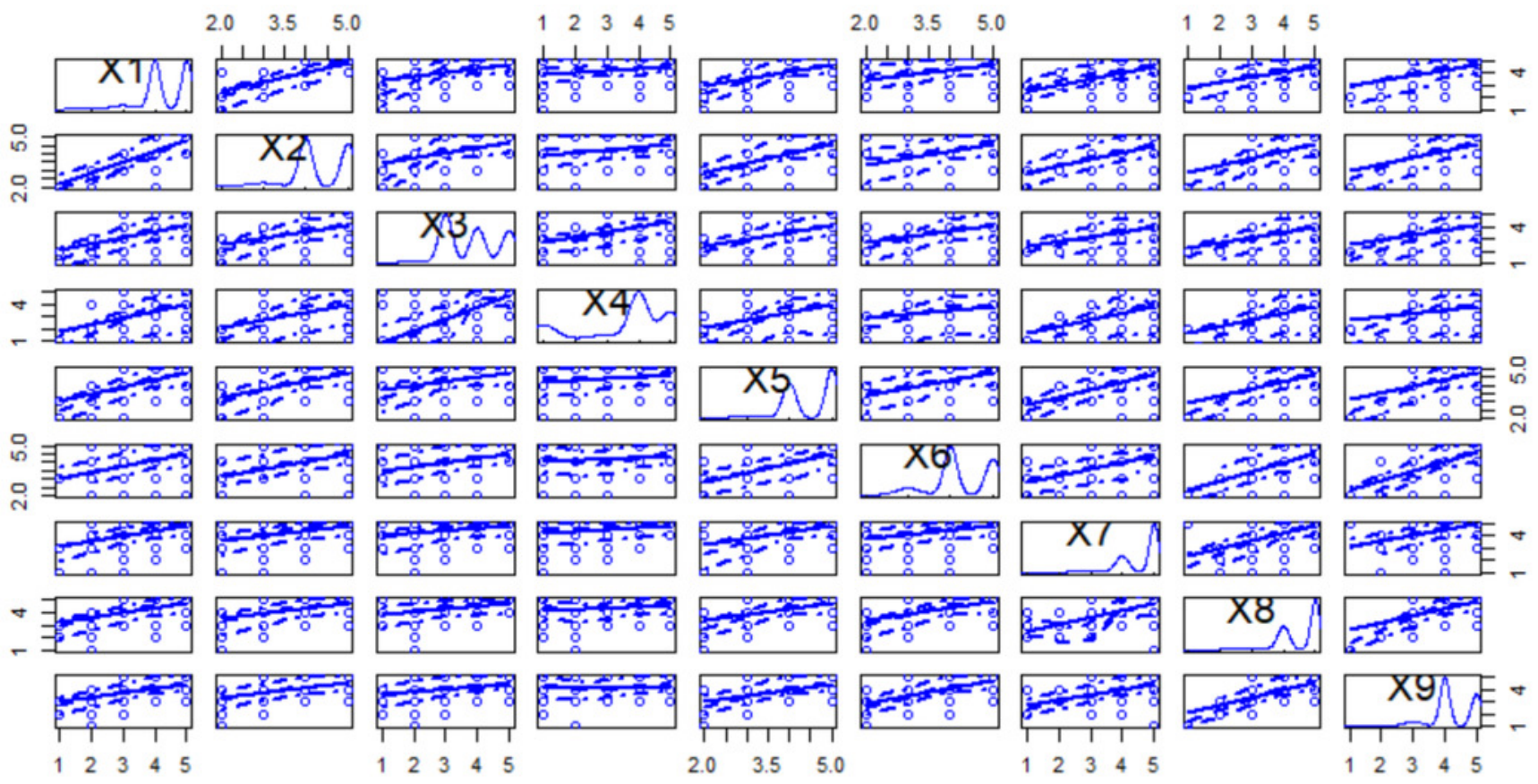


Figure 5

Wrapper method configuration. (Adapted from Bolón-Canedo et al. [36] )

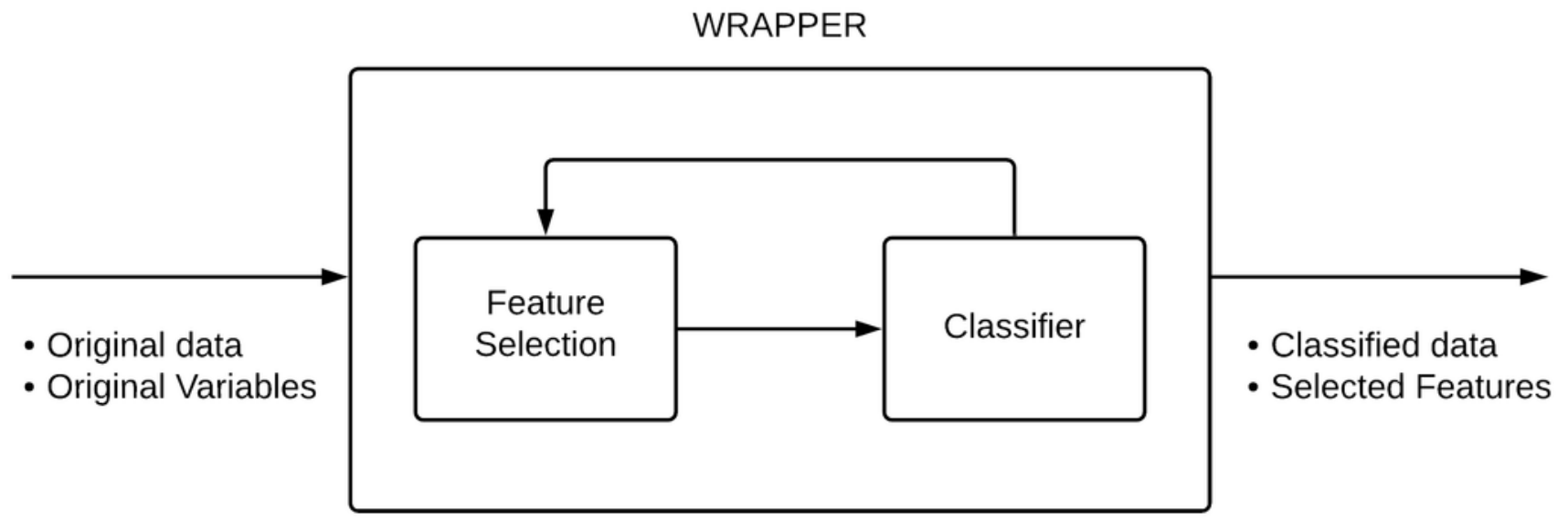


Figure 6

The model to identify relevant quality factors.

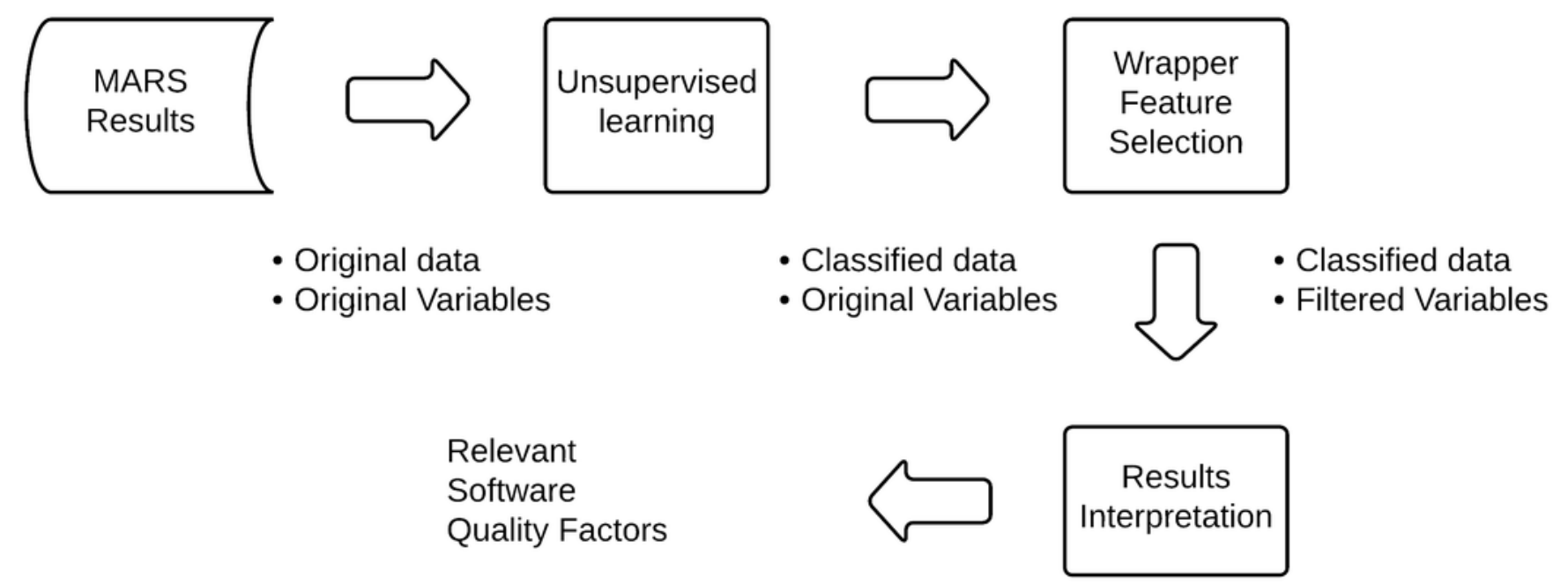


Figure 7

Competitive neural network architecture used for data classification.

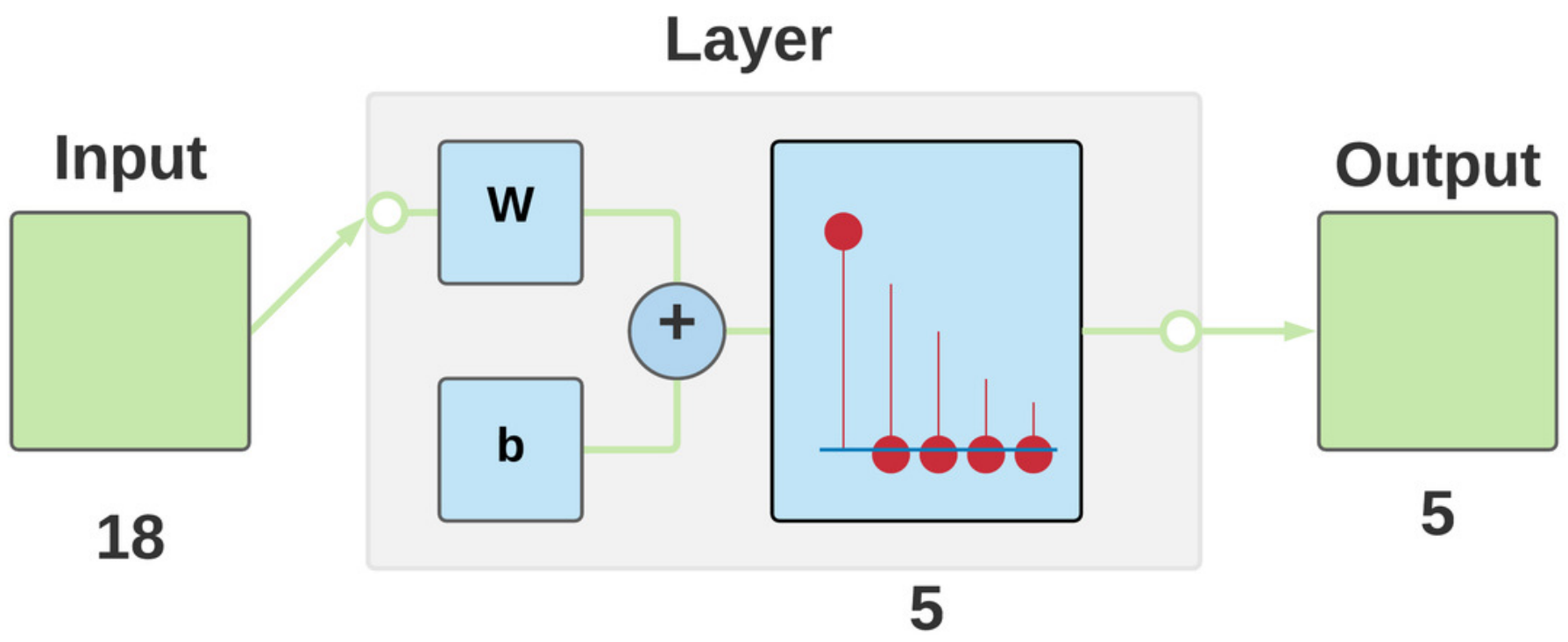


Figure 8

MARS evaluation values and Competitive Classification.

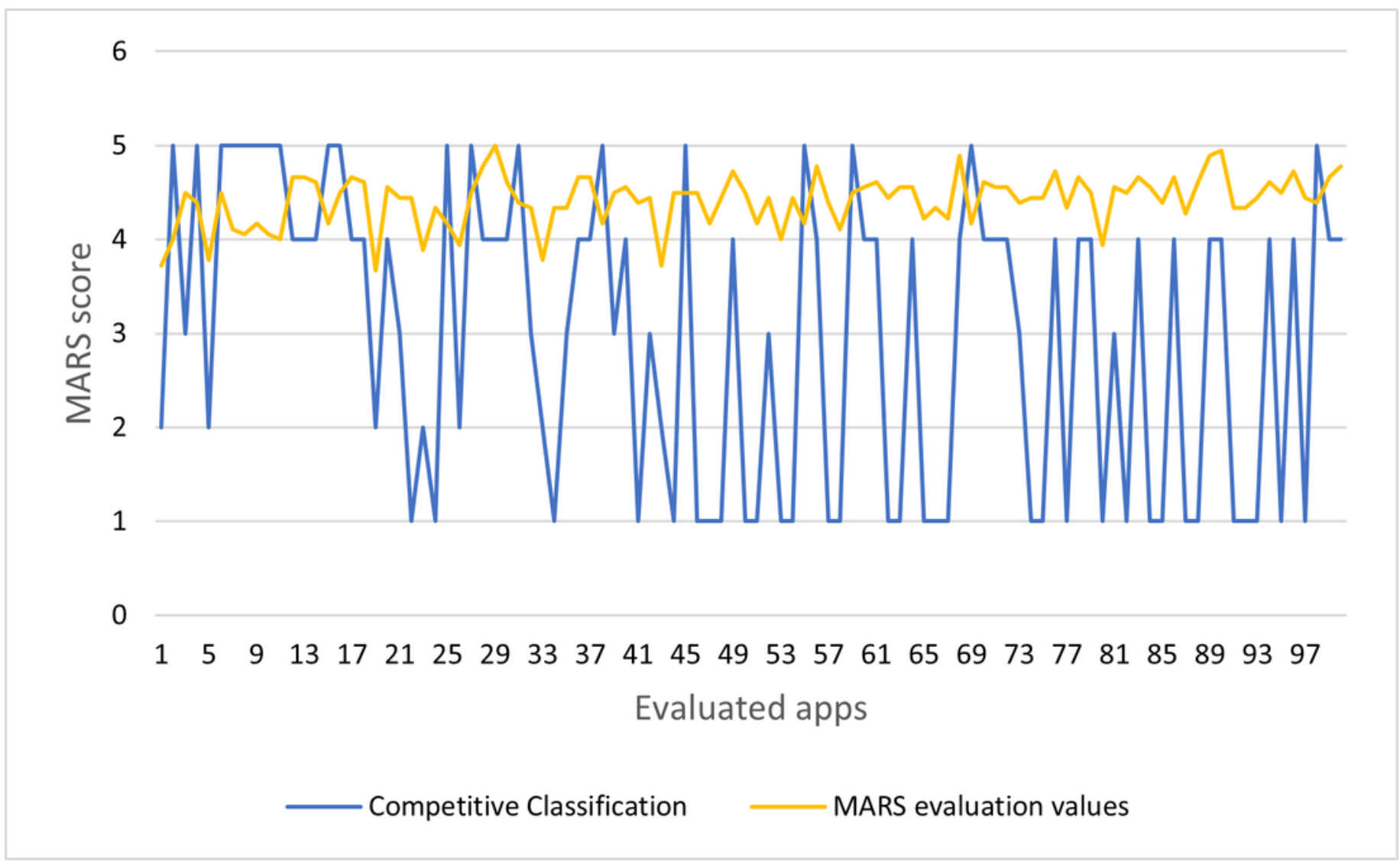


Figure 9

Old and new MARS scores of apps.

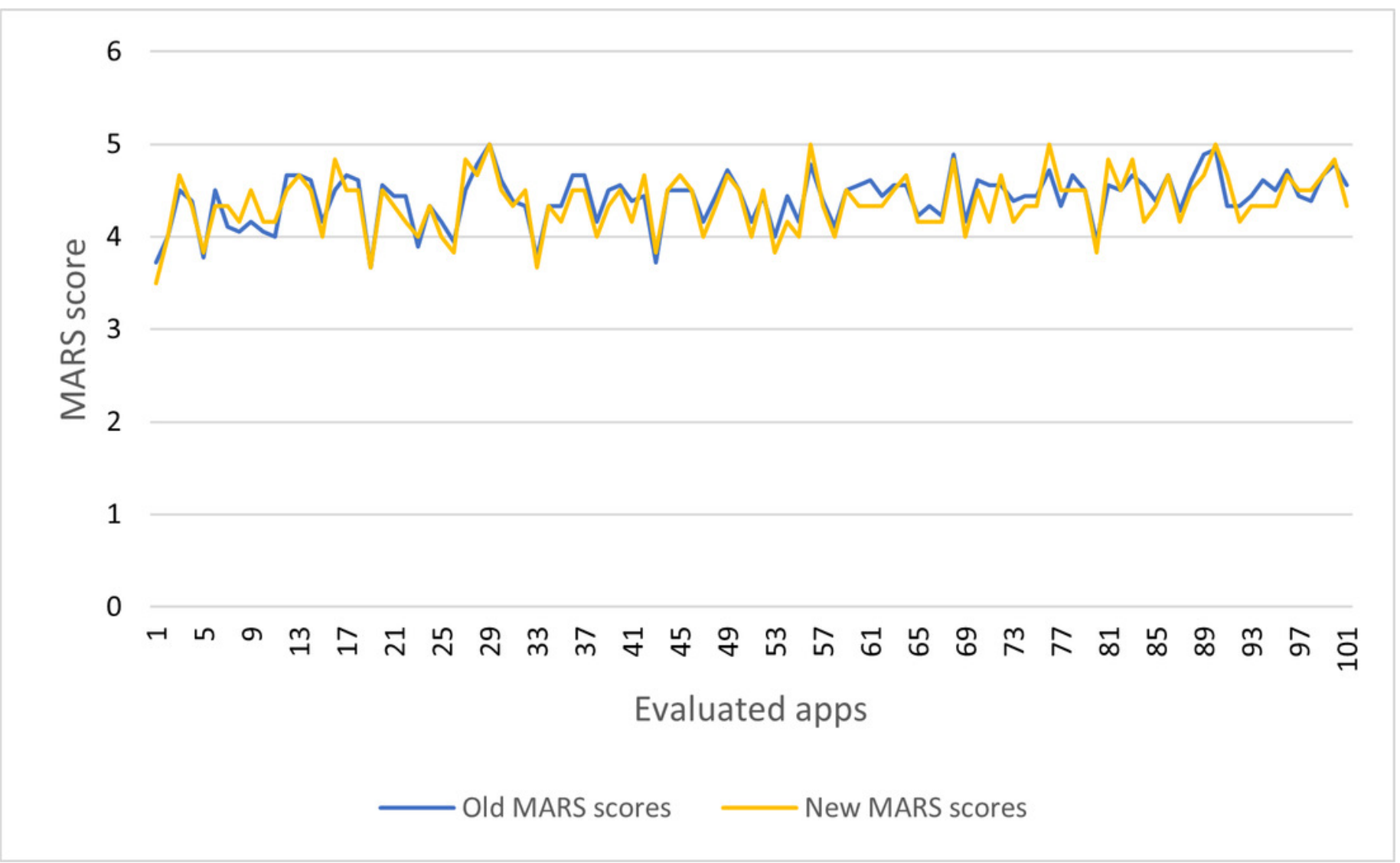


Figure 10

\section{Abductive reasoning process used in this research. The abductive reasoning process (left). The hypotheses and the application process of the new model (right).}
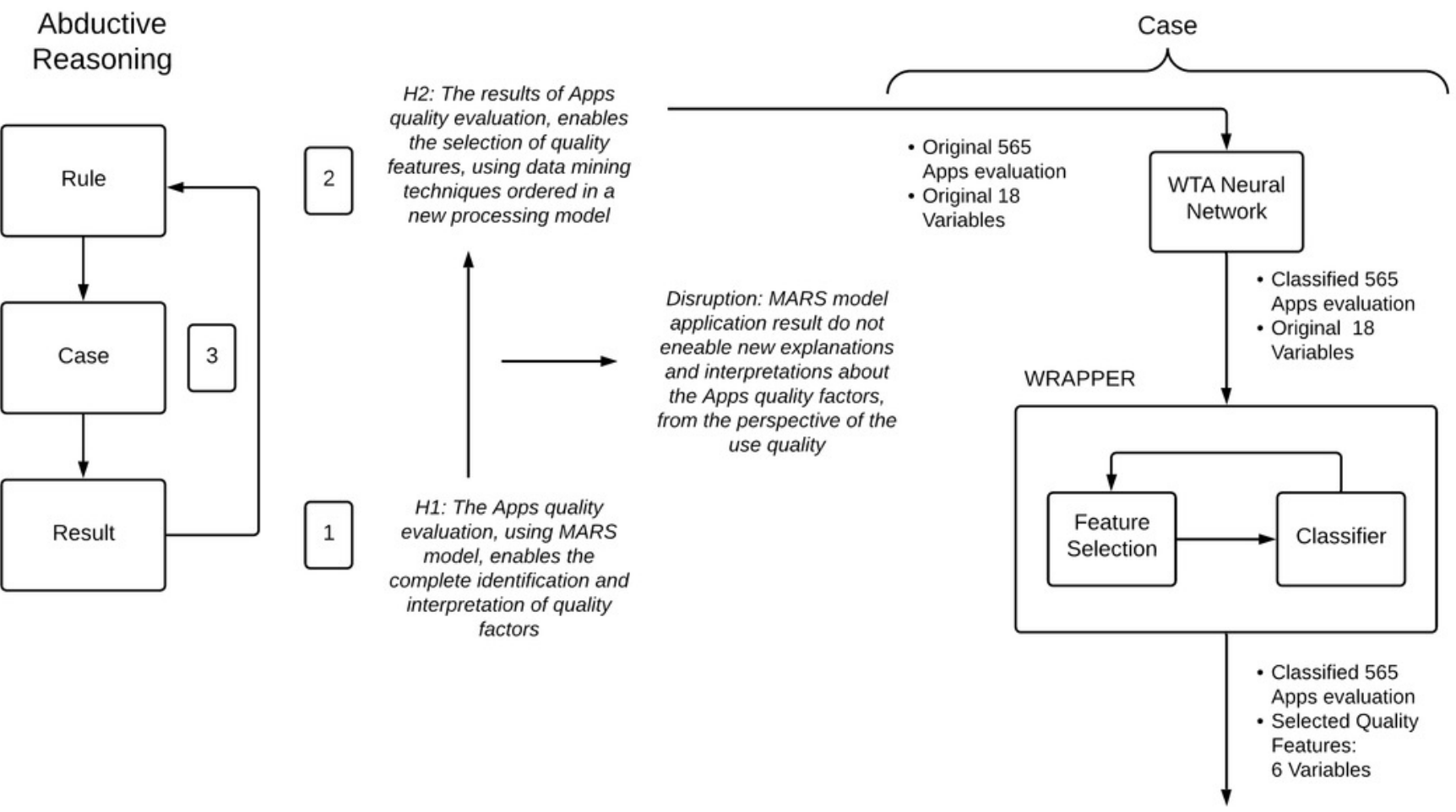


\section{Table $\mathbf{1}$ (on next page)}

Related investigations. 
1 Table 1:

2 Related investigations.

\begin{tabular}{|c|c|}
\hline Reference & Summary \\
\hline $\begin{array}{l}\text { Masterson et al. } \\
\text { [28] }\end{array}$ & $\begin{array}{l}\text { Evaluated } 34 \text { apps with MARS related to heart failure symptom } \\
\text { monitoring and self-care management. Reviewed by the article authors. } \\
\text { Assessed } 23 \text { iOS apps with MARS. The engagement category had the }\end{array}$ \\
\hline Mani et al. [29] & $\begin{array}{l}\text { lowest score and highlights the lack of attractiveness. Reviewed by the } \\
\text { article authors. }\end{array}$ \\
\hline Santo et al. [30] & $\begin{array}{l}\text { A group of } 272 \text { medication reminder apps was classified. Only ten apps } \\
\text { were evaluated with MARS. Reviewed by the article authors. }\end{array}$ \\
\hline $\begin{array}{l}\text { Tinschert et al. } \\
\text { [31] }\end{array}$ & $\begin{array}{l}\text { The study analyzed asthma apps with the potential to promote patient's } \\
\text { self-management. Thirty-eight apps were evaluated. Reviewed by the } \\
\text { article authors. }\end{array}$ \\
\hline $\begin{array}{l}\text { Sullivan et al. } \\
\text { [32] }\end{array}$ & $\begin{array}{l}\text { Describes features of } 40 \text { apps which collect personal data and dietary } \\
\text { behavior. } 20 \text { travel apps and } 20 \text { dietary apps were assessed with MARS. } \\
\text { Reviewed by the article authors. }\end{array}$ \\
\hline $\begin{array}{l}\text { Grainger et al. } \\
{[33]}\end{array}$ & $\begin{array}{l}\text { The study assessed features of apps that assist people to monitor } \\
\text { Rheumatoid arthritis disease activity. } 11 \text { Android and } 16 \text { iOS apps were } \\
\text { evaluated through MARS. Two independent reviewers. }\end{array}$ \\
\hline Wilson et al. [34] & $\begin{array}{l}\text { The study established the quality and sharpness of } 58 \text { apps for drink } \\
\text { driving prevention. Reviewers not specified. }\end{array}$ \\
\hline $\begin{array}{l}\text { Chavez et al. } \\
{[35]}\end{array}$ & $\begin{array}{l}\text { Using MARS, } 89 \text { apps were assessed for diabetes management to see if } \\
\text { they have enough quality to complement clinical care. Reviewed by three } \\
\text { people. }\end{array}$ \\
\hline Yu et al. [36] & $\begin{array}{l}\text { Twelve mHealth apps that give the user behavioral and cognitive skills to } \\
\text { manage insomnia were evaluated with MARS. Reviewed by two authors } \\
\text { of the article. }\end{array}$ \\
\hline Reyes et al. [37] & $\begin{array}{l}\text { Five iOS apps for self-managed balance rehabilitation for older adults } \\
\text { were assessed with MARS. Reviewed by two authors of the article. }\end{array}$ \\
\hline Kim et al. [38] & $\begin{array}{l}\text { Characteristics of } 23 \text { potential Drug-Drug Interaction apps were } \\
\text { reviewed and evaluated with MARS. Reviewed by two testers per app. }\end{array}$ \\
\hline $\begin{array}{l}\text { Escoffery et al. } \\
{[39]}\end{array}$ & $\begin{array}{l}\text { Conducted a systematic review of apps related to epilepsy. Found and } \\
\text { evaluated } 20 \text { apps with MARS focused on educating people about their } \\
\text { condition. Reviewed by a research team. }\end{array}$ \\
\hline Short et al. [40] & $\begin{array}{l}\text { Ten people assessed } 54 \text { apps; the research contributes with new insights } \\
\text { about how to use mHealth apps to assist cancer survivors' physical } \\
\text { exercise. }\end{array}$ \\
\hline $\begin{array}{l}\text { Tofighi et al. } \\
\text { [41] }\end{array}$ & $\begin{array}{l}\text { An interdisciplinary team of clinicians, behavioral informatics, and } \\
\text { public health reviewers trained in substance use disorders conducted a } \\
\text { descriptive analysis of } 74 \text { apps using MARS. }\end{array}$ \\
\hline $\begin{array}{l}\text { Davis and Ellis } \\
{[42]}\end{array}$ & $\begin{array}{l}\text { Participants were randomly assigned to interact with either the high } \\
\text { behavior change technique app, or the low behavior change technique } \\
\text { app using an iPad. Participants then completed a MARS questionnaire. }\end{array}$ \\
\hline
\end{tabular}




\section{Table 2 (on next page)}

Search process. 
1

2

Table 2

Search process.

\begin{tabular}{|c|c|c|c|}
\hline $\begin{array}{c}\text { Search } \\
\text { string }\end{array}$ & $\begin{array}{c}\text { Inclusion } \\
\text { criteria }\end{array}$ & Period & Web site, stores, and repositories \\
\hline $\begin{array}{c}\text { Apps for } \\
\text { life } \\
\text { skills }\end{array}$ & $\begin{array}{l}\text { Educational } \\
\text { apps }\end{array}$ & $\begin{array}{c}\text { Feb } \\
2020- \\
\text { Oct } \\
2020\end{array}$ & $\begin{array}{l}\text { Wikinclusion, Google Play Store, Apple } \\
\text { App Store, PhET, Genmagic.org, } \\
\text { Educaplanet, ARASAAC, } \\
\text { Pictoaplicaciones, Juegos Infantiles Pum, } \\
\text { Edujoy, CEDETi, Educación inclusiva } \\
\text { ONCE, Proyecto DANE, Proyecto } \\
\text { Comunica, pescAPPs, MyFirstApp, } \\
\text { OWLIE BOO, Fundación Orange. }\end{array}$ \\
\hline
\end{tabular}




\section{Table 3 (on next page)}

Devices used for evaluation. 
1

2

3
Table 3

Devices used for evaluation.

\begin{tabular}{ll}
\hline Platform & \multicolumn{1}{c}{ Devices } \\
\hline \multirow{2}{*}{ Desktop } & $\begin{array}{l}\text { Lenovo P50 computers with Windows } \\
10 .\end{array}$ \\
Web & $\begin{array}{l}\text { Firefox browser, version } \\
\text { bits. }\end{array}$ \\
iOS & iPhone 5s, iPhone 6, iPhone 7. 64 \\
Android & Samsung, Sony, Motorola, and Asus. \\
\hline
\end{tabular}




\section{Table 4 (on next page)}

Data extracted from Apps evaluated. 
Table 4

2 Data extracted from Apps evaluated.

\begin{tabular}{|c|c|c|c|c|c|c|c|c|c|c|c|c|}
\hline & Variables & & 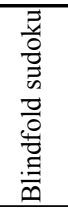 & 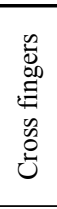 & 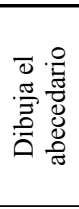 & 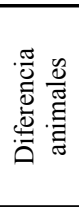 & 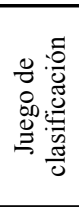 & 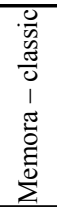 & 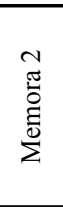 & $\begin{array}{l}00 \\
\frac{n}{0} \\
0 \\
0 \\
0 \\
0 \\
0 \\
0 \\
0 \\
0 \\
0\end{array}$ & 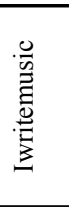 & 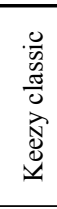 \\
\hline \multirow{5}{*}{ Engagement } & 1. Entertainment & $\mathrm{X} 1$ & 3 & 5 & 4 & 4 & 4 & 4 & 5 & 5 & 5 & 4 \\
\hline & 2. Interest & $\mathrm{X} 2$ & 4 & 5 & 4 & 4 & 4 & 5 & 5 & 5 & 4 & 4 \\
\hline & 3. Customization & $\mathrm{X} 3$ & 3 & 5 & 5 & 5 & 3 & 4 & 4 & 5 & 4 & 5 \\
\hline & 4. Interactivity & $\mathrm{X} 4$ & 4 & 5 & 4 & 5 & 4 & 4 & 4 & 5 & 4 & 4 \\
\hline & 5. Target group & $\mathrm{X} 5$ & 4 & 4 & 5 & 5 & 4 & 5 & 5 & 4 & 4 & 5 \\
\hline \multirow{4}{*}{ Functionality } & 6. Performance & X6 & 4 & 5 & 5 & 5 & 4 & 5 & 4 & 5 & 4 & 4 \\
\hline & 7. Ease of use & $\mathrm{X} 7$ & 4 & 5 & 5 & 5 & 5 & 5 & 5 & 4 & 5 & 5 \\
\hline & 8. Navigation & $\mathrm{X} 8$ & 5 & 5 & 5 & 5 & 5 & 5 & 5 & 4 & 4 & 5 \\
\hline & 9. Gestural design & $\mathrm{X} 9$ & 5 & 4 & 5 & 5 & 5 & 5 & 5 & 5 & 4 & 5 \\
\hline \multirow{3}{*}{ Aesthetics } & 10. Layout & $\mathrm{X} 10$ & 4 & 5 & 4 & 4 & 4 & 4 & 5 & 5 & 5 & 5 \\
\hline & 11. Graphics & $\mathrm{X} 11$ & 3 & 4 & 5 & 4 & 3 & 4 & 4 & 4 & 4 & 5 \\
\hline & 12. Visual appeal & $\mathrm{X} 12$ & 3 & 4 & 4 & 4 & 4 & 4 & 5 & 4 & 5 & 4 \\
\hline \multirow{9}{*}{ Information } & $\begin{array}{l}\text { 13. Accuracy of app } \\
\text { description }\end{array}$ & $\mathrm{X} 13$ & 4 & 5 & 5 & 4 & 4 & 5 & 4 & 5 & 5 & 4 \\
\hline & 14. Goals & $\mathrm{X} 14$ & 4 & 5 & 5 & 5 & 5 & 4 & 5 & 5 & 4 & 4 \\
\hline & $\begin{array}{l}\text { 15. Quality of } \\
\text { information }\end{array}$ & $\mathrm{X} 15$ & 5 & 4 & 4 & 4 & 4 & 5 & 4 & 5 & 5 & 5 \\
\hline & $\begin{array}{l}\text { 16. Quantity of } \\
\text { information }\end{array}$ & $\mathrm{X} 16$ & 4 & 5 & 5 & 5 & 4 & 4 & 5 & 4 & 4 & 4 \\
\hline & 17. Visual information & $\mathrm{X} 17$ & 5 & 5 & 5 & 5 & 4 & 4 & 5 & 4 & 4 & 4 \\
\hline & 18. Credibility & $\mathrm{X} 18$ & 4 & 4 & 5 & 5 & 5 & 5 & 5 & 5 & 5 & 4 \\
\hline & $\begin{array}{l}\text { Original MARS quality } \\
\text { score }\end{array}$ & & 4.0 & 4.7 & 4.7 & 4.6 & 4.2 & 4.5 & 4.7 & 4.6 & 4.4 & 4.4 \\
\hline & $\begin{array}{l}\text { Competitive } \\
\text { classification group }\end{array}$ & & 5 & 4 & 4 & 4 & 5 & 5 & 4 & 4 & 1 & 3 \\
\hline & $\begin{array}{l}\text { New MARS quality } \\
\text { score }\end{array}$ & & 4.2 & 4.5 & 4.7 & 4.5 & 4 & 4.8 & 4.5 & 4.5 & 4.2 & 4.7 \\
\hline
\end{tabular}




\section{Table 5 (on next page)}

Data regression matrix. 
1

2

3 4

5

\section{Table 5}

Data regression matrix.

\begin{tabular}{|c|c|c|c|c|c|c|c|c|c|c|c|c|c|c|c|c|c|c|}
\hline & X1 & $\mathrm{X} 2$ & X3 & X4 & X5 & X6 & $\mathbf{X} 7$ & X8 & X9 & $\mathrm{X} 10$ & X11 & X12 & $\mathrm{X13}$ & X14 & X15 & X16 & $\mathbf{X 1 7}$ & X18 \\
\hline $\mathrm{X} 1$ & 1 & 0.706 & 0.381 & 0.283 & 0.475 & 0.381 & 0.465 & 0.410 & 0.383 & 0.411 & 0.359 & 0.376 & 0.446 & 0.462 & 0.467 & 0.421 & 0.396 & 0.131 \\
\hline $\mathrm{X} 2$ & 0.706 & 1 & 0.402 & 0.318 & 0.546 & 0.443 & \begin{tabular}{|l}
0.399 \\
\end{tabular} & 0.413 & 0.406 & 0.420 & 0.317 & 0.351 & 0.460 & 0.476 & 0.476 & 0.405 & 0.404 & \begin{tabular}{|l}
0.170 \\
\end{tabular} \\
\hline X3 & 0.381 & 0.402 & 1 & 0.650 & 0.381 & 0.340 & 0.282 & 0.315 & 0.278 & 0.325 & 0.541 & 0.503 & 0.359 & 0.438 & 0.407 & 0.435 & 0.391 & 0.050 \\
\hline $\mathrm{X} 4$ & 0.283 & 0.318 & 0.650 & 1 & 0.263 & 0.172 & 0.270 & 0.263 & 0.138 & 0.184 & 0.612 & 0.560 & 0.250 & 0.384 & 0.396 & 0.412 & 0.357 & 0.050 \\
\hline X5 & 0.475 & 0.546 & 0.381 & 0.263 & 1 & 0.519 & 0.488 & 0.448 & 0.437 & 0.478 & 0.266 & 0.301 & 0.442 & 0.492 & 0.417 & 0.423 & 0.438 & 0.219 \\
\hline X6 & 0.381 & 0.443 & 0.340 & 0.172 & 0.519 & 1 & 0.400 & \begin{tabular}{|l|l|}
0.509 \\
\end{tabular} & 0.580 & 0.489 & 0.222 & 0.248 & 0.445 & 0.418 & 0.381 & 0.304 & 0.398 & 0.148 \\
\hline $\mathrm{X} 7$ & 0.465 & 0.399 & 0.282 & 0.270 & 0.488 & 0.400 & 1 & \begin{tabular}{|l|}
0.599 \\
\end{tabular} & 0.431 & 0.359 & 0.306 & 0.342 & 0.401 & 0.512 & 0.416 & 0.404 & 0.446 & 0.104 \\
\hline $\mathrm{X8}$ & 0.410 & 0.413 & 0.315 & 0.263 & 0.448 & 0.509 & 0.599 & 1 & 0.571 & 0.435 & 0.246 & 0.267 & 0.352 & 0.482 & 0.347 & 0.320 & 0.385 & \begin{tabular}{|l}
0.101 \\
\end{tabular} \\
\hline X9 & 0.383 & 0.406 & 0.278 & 0.138 & 0.437 & 0.580 & 0.431 & \begin{tabular}{|l|l|} 
\\
\end{tabular} & 1 & \begin{tabular}{|l|l|}
0.578 \\
\end{tabular} & 0.128 & 0.261 & 0.457 & 0.422 & 0.371 & 0.307 & 0.397 & 0.251 \\
\hline X10 & 0.411 & 0.420 & 0.325 & 0.184 & 0.478 & 0.489 & 0.359 & 0.435 & 0.578 & 1 & 0.236 & 0.324 & 0.459 & 0.428 & 0.436 & 0.354 & 0.399 & 0.297 \\
\hline X11 & 0.359 & 0.317 & 0.541 & 0.612 & 0.266 & 0.222 & \begin{tabular}{|l}
0.306 \\
\end{tabular} & 0.246 & 0.128 & 0.236 & 1 & $\begin{array}{l}0.698 \\
\end{array}$ & 0.316 & 0.383 & 0.425 & 0.431 & \begin{tabular}{|l}
0.348 \\
\end{tabular} & 0.088 \\
\hline $\mathrm{X} 12$ & \begin{tabular}{|l}
0.376 \\
\end{tabular} & 0.351 & 0.503 & 0.560 & 0.301 & 0.248 & \begin{tabular}{|l}
0.342 \\
\end{tabular} & 0.267 & 0.261 & 0.324 & 0.698 & 1 & \begin{tabular}{|l|}
0.429 \\
\end{tabular} & 0.458 & 0.475 & 0.497 & \begin{tabular}{|l}
0.440 \\
\end{tabular} & 0.264 \\
\hline X13 & 0.446 & 0.460 & 0.359 & 0.250 & 0.442 & 0.445 & 0.401 & 0.352 & 0.457 & 0.459 & 0.316 & 0.429 & 1 & 0.620 & 0.632 & 0.520 & \begin{tabular}{|l|l|}
0.564 \\
\end{tabular} & 0.286 \\
\hline X14 & 0.462 & 0.476 & 0.438 & 0.384 & 0.492 & 0.418 & 0.512 & \begin{tabular}{|l|l|}
0.482 \\
\end{tabular} & 0.422 & 0.428 & 0.383 & 0.458 & 0.620 & 1 & 0.635 & \begin{tabular}{|l|}
0.626 \\
\end{tabular} & 0.573 & \begin{tabular}{|l}
0.247 \\
\end{tabular} \\
\hline X15 & 0.467 & 0.476 & 0.407 & 0.396 & 0.417 & 0.381 & 0.416 & 0.347 & 0.371 & 0.436 & 0.425 & 0.475 & 0.632 & 0.635 & 1 & \begin{tabular}{|l|}
0.699 \\
\end{tabular} & \begin{tabular}{|l|}
0.689 \\
\end{tabular} & 0.256 \\
\hline X16 & 0.421 & 0.405 & 0.435 & 0.412 & 0.423 & 0.304 & 0.404 & 0.320 & 0.307 & 0.354 & 0.431 & 0.497 & 0.520 & 0.626 & 0.699 & 1 & 0.728 & 0.226 \\
\hline X17 & 0.396 & 0.404 & 0.391 & 0.357 & 0.438 & 0.398 & 0.446 & 0.385 & 0.397 & 0.399 & 0.348 & 0.440 & 0.564 & 0.573 & 0.689 & \begin{tabular}{|l}
0.728 \\
\end{tabular} & 1 & 0.260 \\
\hline X18 & 0.131 & 0.170 & 0.050 & 0.050 & 0.219 & 0.148 & 0.104 & 0.101 & 0.251 & 0.297 & 0.088 & 0.264 & 0.286 & 0.247 & 0.256 & 0.226 & 0.260 & 1 \\
\hline
\end{tabular}




\section{Table 6 (on next page)}

Summary of the cases classification. 
1

2

3
Table 6

Summary of the cases classification.

\begin{tabular}{ccc}
\hline Class & Number of cases & $\mathbf{\%}$ \\
\hline 1 & 109 & 19.29 \\
2 & 131 & 23.19 \\
3 & 65 & 11.50 \\
4 & 142 & 25.14 \\
5 & 118 & 20.88 \\
\hline
\end{tabular}

